checking germ development, counteracting toxic principles, sustaining vitality of the patient and controlling the tendency to chills. Strychnia given every four hours, combined with pepsin, disinfectants and bitter tonics best suited to the individual case, are essential as well as good nourishing diet given systematically. In debilitated cases stimulants are needed and frequently artificial foods will be required to keep up the vitality of the patient. Of these I have found beef peptonoids, panopeptones and malted milk most reliable. After acute symptoms have subsided some of the most assimilable forms of iron are beneficial. Frequent alcoholic baths with or witiout quinin are useful in tranquilizing the patient, stimulating cutaneous surfaces and checking profuse perspiration.

If the above outlines of treatment with the efficient, systematic, persistent use of the drainage tube are carried out, surgical measures will rarely be required in puerperal infection. I found from inquiry of eighteen leading gynecologists and obstetricians, five were opposed and thirteen in favor of hysterectomy for puerperal infection. Of fifteen cases reported by them up to that time, eight died, making a death rate of $53 \frac{1}{3}$ per cent. The advocates of hysterectomy advise it for disease limited to the uterine body, such as septic metritis, multiple abscesses in uterine wall, uterine thrombo-phlebitis and gangrene of uterus. The diagnosis of such limitation of septic processes is very difficult and mistakes are frequent, with disastrous results. In a majority of cases of septic infection the septic process has extended beyond the uterus, involving other tissues with systemic infection which can not be reached by hysterectomy, but when it is local such an operation is indicated. Most gynecologists that favor hysterectomy advise to curette and tampon the uterus, and if the patient does not improve or grows worse, then remove the uterus. With them it is not a question of diagnosis, but a failure of a certain line of treatment to give relief, which indicates hysterectomy, and that line of treatment frequently creates the demand for the operation in cases of septic infection. Pus accumulations in the pelvis can frequently be relieved by vaginal drainage, as advised by Dr. Henrotin of Chicago, thus saving lives that would be sacrificed by more heroic measures. Pyosalpinx, ovarian abscess, etc., the secondary localized results of infection, should be dealt with on the same principle as when produced by other causes.

In conclusion, I again emphasize the fact that use of the drainage tube, with treatment as outlined above, will save more patients than all surgical measures combined; and more important, the uterus, tubes and ovaries will be preserved for future usefulness and the surgeon's conscience left more at ease.

\section{GONORRHEA IN THE PUERPERIUM.}

Read in the Section on Obstetrics and Diseases of Women, at the FortySeventh Annual Meeting of the American Medical Association at Atlanta. Georgia, May 5-8, 1896.

BY ALBERT H. BURR, M.D.

ATtendiNg PHYSICIAN PROVIDENT hOSPITAL. CHICAGO.

In these latter days of widespread knowledge of aseptic measures for shielding the parturient woman from harm, the occurrence of puerperal sepsis is looked upon, even by the laity, as evidence that some one has blundered, and the attendant is fortunate if he escapes the charge of criminal negligence or inexcusable ignorance. If the infection of the lying-in woman happened only during labor, or her subsequent stay in childbed, the charge might be sustained with justice, but we are convinced that it happens more frequently than is apprehended that an infection has antedated childbed by weeks or months, if indeed it has not preceded conception itself and invaded territory absolutely beyond the reach of any possible antiseptic treatment.

With a unilateral pyosalpinx, or a tubal infection, existing before pregnancy, or a subsequent gonorrheal infection of vulvo-vaginal glands or urethra, who can be certain, even though forewarned, that he can be effectually forearmed against such dangerous and hidden foes?

I confess to a feeling of insecurity in every approaching case of confinement where I know beforehand, or have reason to suspect, the existence of gonorrheal infection, either active or latent. In an obstetric experience of five hundred cases I have had three fatalities, each of which is directly traceable to gonorrhea. In many of the remaining cases of puerperal sepsis, more or less severe, I have found by clinical history or by microscopic verification, the presence of a gonorrheal infection. An epitome of the

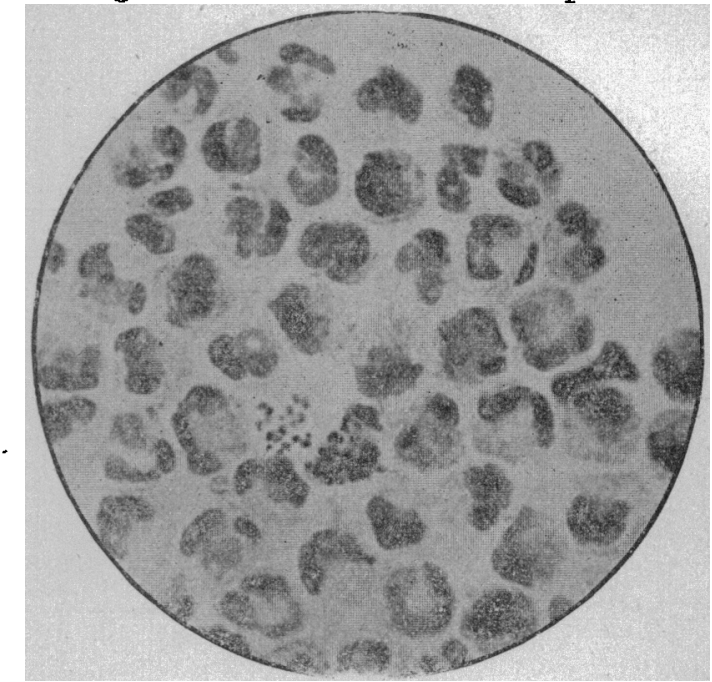

Plate 1; Case V.-Gonococel from ophthalmia neonatorum, fifth day ter birth.

fatai cases, with a few added cases of non-fatal sepsis, culled for their instructive features, may serve to emphasize dangers too often ignored by the unwary. Moreover, it may comfort the troubled soul of some good brother who, believing he has neglected no reasonable precaution for the safety of his patient, has met with disaster where it was least expected. It may enable him in the future to trace the offending cause and place the responsibility where it rightfully belongs.

Case 1.-Elizabeth B., single, aged 20; French Canadian; primipara of vigorous physique, progressed in labor without incident until the separation and expulsion of the placenta brought with it a gush of most offensive fluid, the stench of which drove other attendants from the chamber. No odor was present at the rupture of the amnion. Nothing abnormal was apparent in the secundines. The child was robust. Here was a case of encysted septic material behind the placental attachment which no possible foresight or treatment could have reached in preparation for an aseptic confinement. Thorough infection of the whole placental site and of the parturient canal with a most deadly poison was instantaneous and inevitable. Peritonitis developed in thirty-six hours and ran its distressing and fatal course in less than a week, despite antiseptic uterine irrigations and other recognized treatment. In the absence of an autopsy the only logical conclusion is that the location of the decidua over the cornua had converted an 
infected tube into a closed sack which discharged its saprophytic contents into the uterus when the detachment of the placenta had freed its uterine orifice. The vocation of the woman makes gonorrhea the most probable cause of a pyosalpinx.

Case 2.-Emma M., aged 20 years: German; married ten months; remarkably strong in physique; consulted me soon after marriage for metrorrhagia. Examination revealed an acute vaginitis, characteristic of gonorrhea. Subsequent examination of the husband showed an acute urethritis. These symptoms in the wife yielded promptly to treatment and pregnancy soon put an end to metrorrhagia. Both husband and wife, however, had recurrent attacks of sub-acute gonorrhea during the wife's pregnancy. Confinement was normal, on March 12, 1888. Antiseptic vaginal irrigation was practiced for several days. No untoward symptoms resulted until March 20, the eighth day, when a severe chill occurred followed by high fever, but without pelvic symptoms which never became a factor throughout her fatal illness. General systemic intoxication, however, persisted to a high degree. Knowing the previous history, uterine irrigation was practiced twice daily. On March 24 temperature suddenly arose to 108 degrees, which was quickly reduced by cold packs and antipyrin. Dr. H. W. Byford saw the case in consultation the following day and curetted for diagnostic purposes, with negative results. March 30 temperature reached 108.5 degrees with delirium and typhoid state, severe arthritis of shoulder and hip joint, followed with temperature of 103 to 104 degrees, till fatal termination April 5, on the seventeenth day of fever

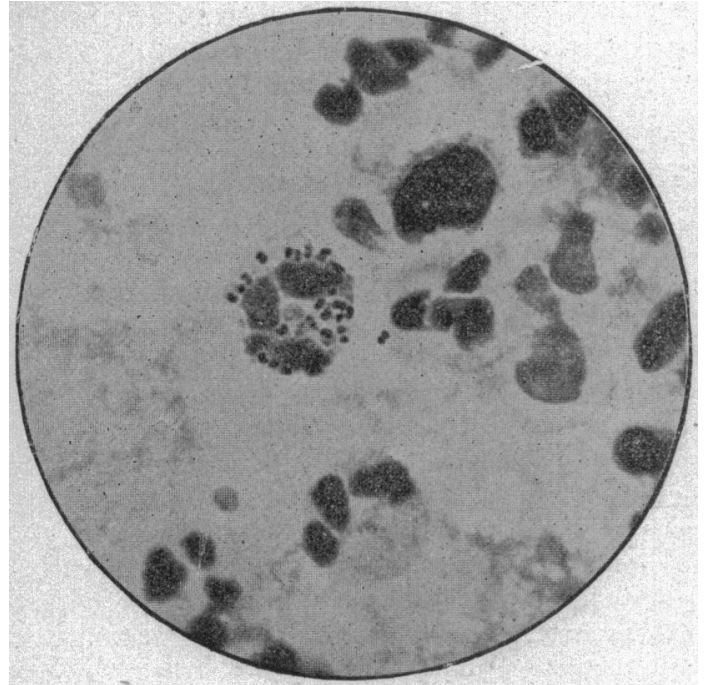

Plate 2; Case V.-Gonococci from cervical discharges, ten weeks after childbirth. Subinvolution.

and twenty-fourth day from confinement. The good health of the patient at childbirth, the sudden onset of high fever, the absence of bowel symptoms, exclude typhoid fever. My distinguished consultant concurred with me that gonorrheal infection was the most probable direct or indirect cause in this most singularly virulent case.

Case 3.-Luella B., American, single, aged 18, consulted me because she had not menstruated for several months. Under a suspicion of pregnancy an examination was obtained, reveal. ing a four months' pregnancy and an acute vaginitis, believed to be gonorrheal. The case was lost sight of until summoned to her confinement. Labor was normal in all respects. On the fourth day there was a chill followed by high fever from an acute metritis. This was controlled after two or three days and patient was dismissed on the eighth day. In one week there was a recurrence of symptoms which again responded to treatment as before. Patient was about the house again when she had a second recurrence, under the care of another physician, and died, as I learned, one month after childbirth.

The following three cases of puerperal sepsis are interesting on account of microscopic verifications.

Case 4.-Ida H., four months married, was delivered at full term by a midwife. On the fifth day after the confinement I found her with a temperature of 105 degrees and an acute arthritis of hip joints with immobility of lower extremities. The child was suffering from acute ophthalmia. The pus, from which a slide was prepared, showed the gonoccocus in abundance. The father acknowledged having had gonorrhea a few months before marriage. Mother and child made a good though tedious recovery under appropriate treatment.

Case 5.-Mrs. Ida T., age 21 ; ten months married. Labor normal. On the fifth day child developed ophthalmia of gonorrheal infection. (See plate I.) The condition was at once explained to the father, who stated that he had an attack of gonorrhea four months before marriage, but considered himself cured at the time he wedded his wife. He remembered having had some gleet (?) afterward. On the seventh day the mother had a chill with fever and acute arthritis of shoulder joint of right side. As pelvic symptoms were absent, no irrigations were given. Mother and child were discharged conva. lescent on the twelfth day. Ten weeks later the mother came to my office suffering from sub-involution. Microscopic examination of cervical discharges showed gonococci. (See plate II.) Case yielded promptly to treatment.

Case 6.-Mrs. Amelia S., age 26, primipara, was well advanced in second stage of labor when seen for the first time. Labor terminated without incident. Child developed gonorrheal ophthalmia on the fifth day. (See plate III.) On the tenth day the mother was dismissed, after a good recovery, much to the relief of an anxious medical attendant. Two days later an urgent call in the early hours of morning cut short my slumber and dispelled my sense of security. Patient had a violent chill in the night, followed by high fever, with acute metritis and pelvic pain reflected to the diaphragm, causing dyspnea and a sense of suffocation. Before making intrauterine irrigation a slide from the cervical discharge was obtained and the inevitable coccus came to light. (See plate

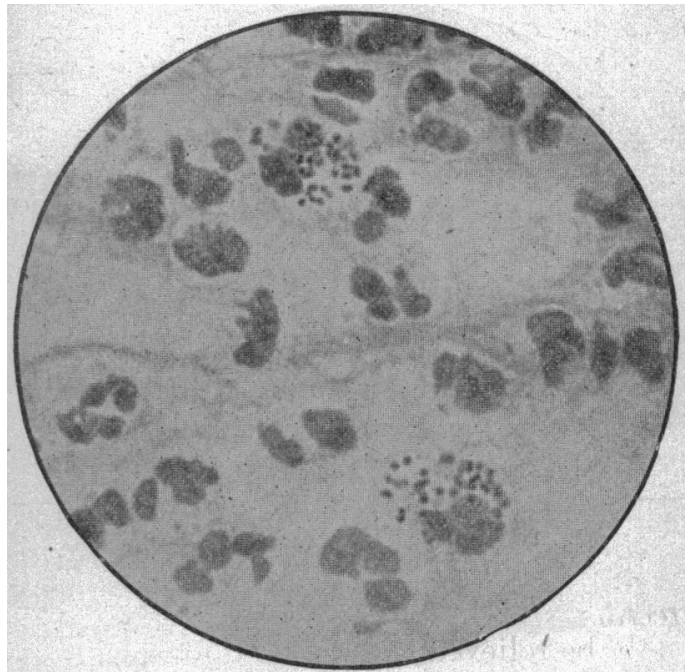

Plate 3; Case VI.-Gonorrheal ophthalmia in babe fire days old

IV.) The husband being an actor an investigation behind the scenes was undertaken, disclosing a history of infection a few weeks before the confinement of his wife, whom he unfortunately infected also before he was aware of his own condition. This complication was almost a fatal experience, but finally yielded and the mother was again convalescent in one month. The ophthalmia in the child was also quite obstinate for some time, though daily applications of silver solution, grains $x \times x$ to the ounce, was faithfully and thoroughly applied with brush to the whole conjunctival sack.

This list of well determined gonorrheal sepsis in childbed could be extended, but enough has been detailed to serve our purpose.

To summarize: All the above cases were primiparæ much above the average in physique and general good health. Their delivery was without complication or instrumental interference. All necessary examinations or manipulations were guarded against sepsis. In no case was there more than the usual slight laceration. In all, the presence of gonorrhea is closely proven except in case 1, where the tubal abscess is believed to have been the result of a gonorrheal infection previous to conception. Three of the cases developed rheumatoid arthritis during the pyrexia. This is a well known complication due to systemic infections of the gonorrheal germs or their ptomains. 
No doubt exists in my mind from the evidence in the cases above enumerated and others which $\Upsilon$ could add to the number, that the microscope and other means of investigation as to the gonorrheal infection would clear up the etiology of many septic complications and fatalities in childbed. These unnecessary woes too frequently attendant on motherhood, and the sad lessons taught on the tables of our gynecologists, take away the bliss of ignorance from our profession and add to our knowledge the responsibility and imperative duty of vigilant measures for prophylaxis. Every case of gonorrhea in the male should be treated as a matter of serious import, for even though it may seem trivial to him, it may blight the lives of those to whom he may and probably will transmit the disease. Who of us having daughters do not look with apprehension as to their future health and safety in the relation of wives and mothers? If "whatsoever a man soweth, that shall he also reap," were harvested by himself only, the baneful results were evil enough, but when he sows pathogenic seed to germinate in the organisms of innocent, unsuspecting, unprotected mothers and babes the calamity is ten fold, for the perils of death, of invalidism, of sightless eyes, are

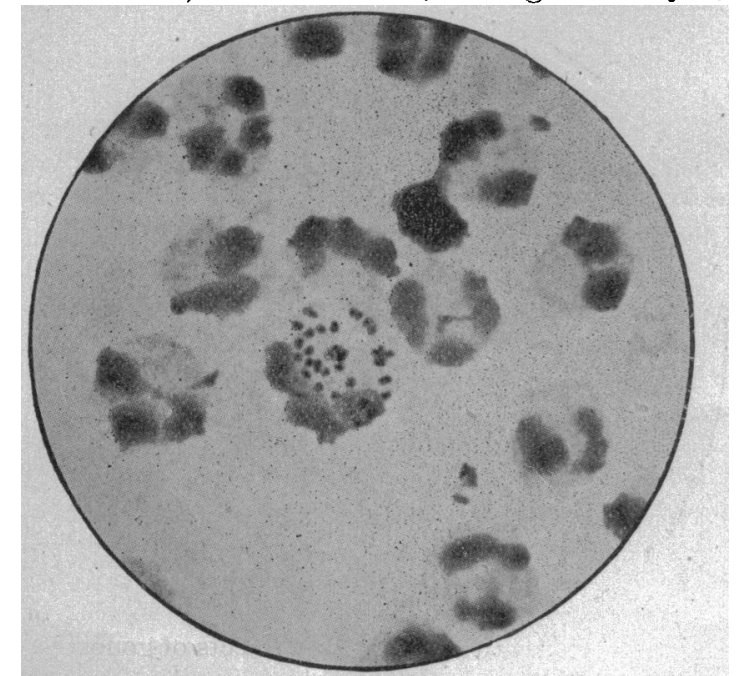

Plate 4; Case VI.-Gonococci from cervical secretions, twelve days after confinement. Acute metritis und pelvic cellulitis.

far beyond the dangers he willingly hazards to gratify his sinful lusts.

To what extent these things prevail can not be fully known, but every physician who is not stupidly ignorant or wilfully blind to the fact, knows that they are of very frequent occurrence. When we consider that the majority of males (Ricord estimates 80 per cent. for France; Noeggerath believed the same ratio held good for New York City) have been affected at some period of life with a gonorrheal experience more or less persistent, how can it be otherwise, under the present sociologic conditions, that a large number of prospective mothers in or out of wedlock, innocent victims or particeps criminis, become the unfortunate hostesses of pathogenic germs that place them in dire perils at childbirth, perils which are all the more deplorable because unnecessary and preventable.

Noeggerath believed that "90 per cent. of males affected with gonorrhea remain uncured, and of every hundred women who had married men formerly affected by gonorrhea hardly ten remain well." These may seem like extreme views, but even liberally discounted the figures would still show a lamentable state of affairs.
Prince reported that 60 per cent. of the blind in the asylum in Jacksonville, Ill., were the victims of oph. thalmia neonatorum.

Noeggerath gave us the warning that gonorrhea was the most fruitful cause of woman's pelvic woes long before Neisser discovered the specific diplococcus, so beautifully demonstrated in the photo-micrographs exhibited with this paper.

Man is so constituted as to remain indifferent to many evils by reason of their frequent and longaccustomed occurrence. $\mathrm{He}$ is also averse to any measures that curtail the indulgence of his animal instincts, regardless of consequences to others, but the day will come in that higher evolution of preventive medicine when an enlightened public will demand protection by quarantine, by restrictive legislation and by penal enactments against individuals infected with this loathsome and dangerous disease.

It will be a righteous advance when the State shall afford some protection to the innocent by placing legal barriers to the marriage of all individuals who, by competent medical inspection, can not present certificates of freedom from all contagious and hereditary diseases. Nor should the line be drawn on the male sex only. The advanced medical woman could confer no greater boon upon her sex and humanity than the accomplishment of reforms along these lines.

2036 Indiana Avenue.

DISCUSSION ON PAPERS OF DRS. MONTGOMERY, KIME AND BURR.

Dr. E. E. Montgomery, Philadelphia-In regard to the treatment suggested by Dr. Kime, I must agree with him as to the inadvisability of using the curette in cases of puerperal sepsis. I do not believe it has any special advantage, because the streptococci are buried in the tissues to such a degree that they are notremoved by an instrument, and an increased irritation is produced by the curette which furnishes a more favorable soil for the development of the trouble. I believe that the future treatment of puerperal diseases will be in the use of serumtherapy. It is believed that an individual can be rendered immune to further ravages of germ products, and that the first thing to be done in the treatment of such cases, after a diagnosis of sepsis or sapremia has been made, should be the administration of antitoxin in such doses as will render the patient immune to further ravages. The local manifestations should be treated without fear of further development. Dr. RANDELL, Baltimore--I had quite an extensive experience in the management of severe cases of puerperal sepsis. A large number occur in the practice of every general practitioner that are simply mild infections due to putrefactive organismis; a number of cases occurring after abortion are of this variety, and the only thing necessary is to thoroughly clean out the uterus, making some antiseptic application to the endometrium. Under the various methods that are used the cases recover after one local treatment. But we have a large number of cases in which there is. either a mixed infection or in which the streptococcus plays usually a very important part in the uterus of women after confinement, and these cases have to be attacked most energetically or they will die. If any practitioner will keep actively at work in treating them, he will cure a large proportion. A great many cases of puerperal sepsis which have come under my observation and care have been severe ones. My treatment has been similar to that which has been advanced in the paper, with some slight modifications. Some of these patients can be saved by washing out the uterus with an antiseptic solution every six hours, if the infection has not advanced too far. In some of the cases you may have a superficial gangrene at the placental site, due to streptococcus infection, and you should use the curette in 
order to remove the gangrenous material, then apply inside the uterus a 15 per cent. solution of carbolic acid and 10 per cent. of iodin.

Dr. Joseph Eastman, Indianapolis -I believe that many cases of puerperal infection are largely due to the filthy poisonous syringes that are used by midwives. I recall an instance where I jokingly asked if they had a good syringe that I could use. Yes, was the reply. It was one that had been used by the neighbors for three or four years. Taking syringes and dipping them in bichlorid of mercury solutions is useless. The nozzles of such syringes should be sterilized by boiling before they are used. But far better than that is the idea to raise the patient sufficiently in bed to empty the uterus by vital force. Drainage by packing with gauze and curetting are carried to extremes. Savage, in his work on the "Ana tomy of the Female Pelvic Organs," long ago taught an important physiologic principle. It is this: If there is a foreign substance in the cavity of the uterus, the cervix contracts tightly to hold it in. If there is a foreign body in the cervix, the fundus forcibly contracts to expel it. With the fundus continually contracting, the hyperplastic tissue is reduced and the absorption of septic material is interfered with.

I protest against scraping the cavity of the uterus with a sharp curette. I would not think of using anything sharper than a dull wire curette in the puerperal uterus.

The gentleman who read the last paper made an important point; one we can not mention without some feeling of concern. It almost makes one shudder to think of the number of young men who are not permanently cured of gonorrhea. There may be a granular patch in the urethra, or a stricture above it, and the poison is conveyed to the virgin wife after marriage.

DR. J. T. Priestrey, Iowa-I desire to say a few words from the standpoint of a general practitioner. I practiced the obstetric art before the introduction of the antiseptic practice of midwifery, and I have practiced it since with very much better results than before. I thank Dr. Montgomery for the suggestion of serum therapy. I think it a good one, and if carried out will be of benefit in many cases.

I prepare myself for attendance upon an obstetric case the same as I do for an abdominal operation. I think the same cleanliness of hands and other things brought into contact with the patient should be carried out. I do not use any intrauterine antepartum douche. I insist that when the douche is given the point of the nozzle of the syringe should be boiled. I do not hesitate to go from a case of scarlet fever or any contagious case, and attend a case of midwifery, if $I$ have time to prepare myself.

My practice covers a territory in which women are largely attended by midwives during confinement, and I see many cases in which there is elevation of temperature after delivery. I do not wait to find out whether it is sapremia or septic infection, but take a Mundé curette, which is very large, almost the size of the curve of my finger, and use it to curette the uterine cavity. It has no sharp cutting edge, and with it the uterus can be easily scraped. At the same time I flush it with sterilized hot water. I formerly put in guaze packing. I did not realize at first that there was a difference between tamponing and draining by the use of gauze. Where tampons are used we simply do much harm. If a piece of wicking is used we can establish drainage and do good, in many of my cases I drain with ordinary iodoform wicking, after cleansing the uterine cavity with a dull curette. I think I have benefited a great many of my patients by this procedure.

Dr. Henry P. Newman, Chicago-In regard to the uterus in the puerperal condition it is usually large and flabby and will fall with the turning of the patient to either side, or if the patient is lying on the back it is very apt to be more or less retroverted. Here is where I object to the use of the tube, excellent as it is alone, it does not drain. In other words, you do not drain with a tube up-hill. If you supplement your drainage with iodoform wicking, you will find that it is more efficient and you will accomplish much more than by means of a tube. It is my practice to use wicking rather firmly in the upper part of the uterus. I do this not for drainage alone, but to stimulate uterine contractions in the lower half as it approaches the internal os. It is placed simply for drainage and not for the purpose of a tampon in any sense. It is applied loosely and a single strand projects from the surface. Under these circumstances drainage is efficient either with or without the rubber tube.

With reference to the use of the curette I am not partial to a sharp one, although a dull one or the finger may be used to remove débris in puerperal cases. However, in a patient after abortion $I$ resort to curettage and use it in conjunction with mopping out the uterus the same as in a non-puerperal uterus, and 1 rely more upon swabbing than irrigation. If the microorganisms are beyond the reach of the curette, they are assuredly beyond the reach of the ordinary antiseptic wash. But with stronger solutions than those mentioned, namely, phenol or iodized phenol, which is practically 50 per cent. each of iodin and carbolic acid, I swab out the entire uterine cavity, and follow this with washing by sterilized water. These cases are not disturbed if the temperature does not rise, or symptoms of a grave order do not again manifest themselves. Irrigation, if it is done at all, I believe, is necessary in gonorrheal infection.

DR. R. R. Krme, Atlanta-I would call attention to and emphasize the fact that drainage can not in all cases be attained by gauze, and in some instances it is necessary that the gauze be supplemented with a drainage tube. If you have a large flabby, retroverted uterus, you may introduce a strip of gauze and you will not drain the hemorrhage. If you put in a strip of gauze by the side of the tube, you may carry off the liquid and solid materials. We should remove the septic condition.

Dr. A. H. Burr, Chicago-The object of my paper was to call attention to a matter which seems to have been neglected, and which is an important factor in puerperal complications. Perhaps all of the infection that occurs to innocent women is the result of ignorance on the part of the husband, or he who later becomes the husband. There are thousands of young men who never would become the subjects of gonorrheal infection if they were properly enlightened, and if perhance they contracted this disease, certainly would not infect the innocent. I do not think it right that we should dismiss this subject in a trivial manner, by any means. I do not suppose we can wipe out this matter of gonorrheal infection by legislation any more than we can wipe out original sin by legislative enactment. But we can educate the young men as to the dangers of gonorrheal infection. I believe I am within bounds when I make the assertion, that if it were not for gonorrhea and its sequelæ, the gynecologists would lose half their patronage.

\section{DEGENERATIVE CHANGES THAT OCCUR IN UTERINE FIBRO-MYOMATOUS} GROWTHS.

Read in the Section on Obstetrics and Diseases of Women, at the Forty-seventh Annual Meeting of the American Medical Association held at Atlanta, Ga., May 5-8, 1896.

BY AUGUSTUS P. CLARKE, A.M., M.D. CAMBRIDGe, Mass.

The presence of uterine fibroid growths has for the past few years given rise to much discussion among gynecologists; the consideration of the surgical treatment they have demanded has received much attention, and measures of procedure, in some instances apparently opposite, have sometimes been adopted. 